\title{
A Reconfigurable Buck, Boost, and Buck-Boost Converter: Unified Model and Robust Controller
}

\author{
Martín Antonio Rodríguez Licea $\mathbb{D}^{1},{ }^{1}$ Francisco Javier Perez Pinal, ${ }^{2}$ \\ Alejandro Israel Barranco Gutiérrez $\mathbb{D}^{\mathbb{D}}{ }^{1}$ \\ Carlos Alonso Herrera Ramírez, ${ }^{1}$ and Jose Cruz Nuñez Perez ${ }^{3}$ \\ ${ }^{1}$ CONACYT-Instituto Tecnológico de Celaya, Departamento de Ingeniería Electrónica, 38010 Celaya, GTO, Mexico \\ ${ }^{2}$ Instituto Tecnológico de Celaya, Departamento de Ingeniería Electrónica, 38010 Celaya, GTO, Mexico \\ ${ }^{3}$ Instituto Politécnico Nacional, CITEDI, 22435 Tijuana, BC, Mexico
}

Correspondence should be addressed to Martín Antonio Rodríguez Licea; martin.rodriguez@itcelaya.edu.mx

Received 6 September 2017; Revised 24 January 2018; Accepted 31 January 2018; Published 5 March 2018

Academic Editor: Aimé Lay-Ekuakille

Copyright (C) 2018 Martín Antonio Rodríguez Licea et al. This is an open access article distributed under the Creative Commons Attribution License, which permits unrestricted use, distribution, and reproduction in any medium, provided the original work is properly cited.

\begin{abstract}
The need for reconfigurable, high power density, and low-cost configurations of DC-DC power electronic converters (PEC) in areas such as the transport electrification and the use of renewable energy has spread out the requirement to incorporate in a single circuit several topologies, which generally result in an increment of complexity about the modeling, control, and stability analyses. In this paper, a reconfigurable topology is presented which can be applied in alterative/changing power conversion scenarios and consists of a reconfigurable Buck, Boost, and Buck-Boost DC-DC converter (RBBC). A unified averaged model of the RBBC is obtained, a robust controller is designed through a polytopic representation, and a Lyapunov based switched stability analysis of the closed-loop system is presented. The reported RBBC provides a wide range of voltage operation, theoretically from $-\infty$ to $\infty$ volts with a single power source. Robust stability, even under arbitrarily fast (bounded) parameter variations and reconfiguration changes, is reported including numerical and experimental results. The main advantages of the converter and the robust controller proposed are simple design, robustness against abrupt changes in the parameters, and low cost.
\end{abstract}

\section{Introduction}

It is widely known that the main goal of power electronic converters (PEC) is to convert energy from one stage to another in the most efficient way [1-5]. Early stages of Power Electronics in the "Modern Era" were devoted to the development of devices, accurate modeling of topologies, advances of reliable architectures, and design of high-performance control laws [6-8]. Later, researchers work was to improve technology from devices and overall converters efficiency [9]. In recent years, the researching goals in the development of PEC are system cost reduction, new interconnection technologies for ultrahigh power density systems, wide temperature operation range, smart power conversion, simple power management, and high level of integration [10].

In particular, examples of integrated PEC can be found in a wide range of different applications. For instance, in
[11] an exhaustive review of converters configuration, power quality behavior, design guidelines, and overall selection was performed. In [12] an adaptive, proportional-integral (PI) controller was proposed for a power factor correction converter; a comparison between two conventional PI structures and adaptive one was performed. An interesting 12-polygonal space vector modulation technique in a matrix converter for direct torque control was proposed in [13]. An application to induction motors with variable speed was given achieving a significant reduction in torque ripple, noise, and vibration, shown by numerical simulations and extensive experimental tests. Evaluation and comparison of several multicarrier pulse width modulation (PWM) methods applied to solar powered multilevel inverters were reported in [14]. It was stated that switching losses, total harmonic distortion (THD), and electromagnetic interference (EMI) generated depend on the PWM method used. 
Actually, the integration of various PEC in a single circuitry (reconfigurable PEC or RPEC) is preferred because it has several advantages such as low cost, portability, modularity, an increment of power density, and a wide operation region [15-28]. However, this increment of versatility rises the modeling and control complexity. In order to overcome this concern, some advance control methodologies that work in operation regions rather than single operation points have been proposed by researchers, for instance, by intelligent [2937], pulse adjustment [38], and hybrid controllers [39].

Few studies have investigated the development of RPEC and even of integrated PEC considering them as a class of polytopic switched system (PSS) [40]. Particularly, a PSS is a class of hybrid system constituted of a set of piecewise polytopic systems that commute owing to a discrete event. Those systems have the advantages that the switching principle can be stated by design rules; as a result, the PSS representation allows designing robust controllers with quantitative bounds of parameter variation, and the stability even among switching events is ensured, for example, by a common Lyapunov function. The controllers based on PSS can have high flexibility and adaptability in a large set of operating conditions like current or voltage ripple, changes on power load or voltage source, and continuous, discontinuous, or critical operation mode, among others.

In this paper a reconfigurable Buck, Boost, and BuckBoost DC-DC converter (RBBC), unified/generalizedaveraged PSS model of the RBBC, a robust voltage-mode controller, and a Lyapunov stability proof in closed-loop are proposed in order to advance our knowledge of integrated PEC and RPEC from a PSS perspective. This RPEC was developed to provide a unique, low-cost, and stable solution to several problems arising in Electric Vehicles and smart grid scenarios. For example, in an Electric Vehicle, a single solution to driving the power from the battery to the main motor is desirable in a wide range of speed forward direction and in low speed reverse direction while several parameters are dynamic. The model, controller, and stability proof presented can be used for any combination of the aforementioned converters, even in an on-the-fly reconfigurable scheme. Numerical data for a demonstrative Proportional-Derivative (PD) controller, implemented in an experimental testbed, are presented.

This paper is organized as follows. The unified Buck, Boost DC-DC converter (UBBC) and the methodology for the modeling are described in Section 2. An insight into components selection is described in Section 3. The proposed control and robust stability analysis of the output voltage in closed-loop are given in Section 4. Section 5 shows numerical simulations. Practical results of the proposed converter during start-up and steady state and between converter transitions using an experimental testbed are shown in Section 6. A final discussion is given in Section 7 and conclusions and final remarks are given in the last section.

\section{Modeling}

In this section, the schematic and the operating modes of the $\mathrm{RBBC}$ are presented; later a polytopic representation of the

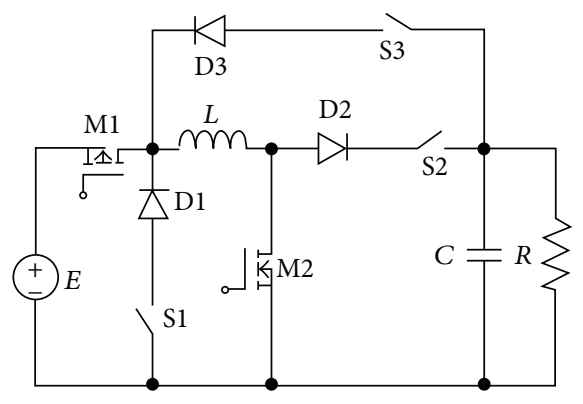

Figure 1: Proposed RBBC.

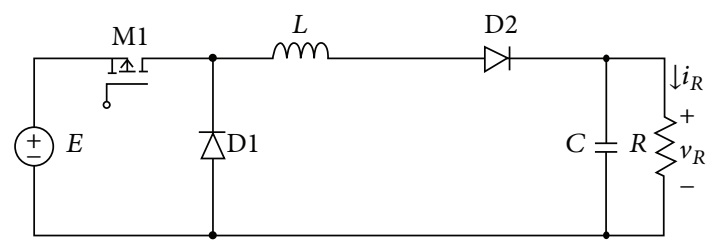

Figure 2: Mode 1 of the proposed RBBC.

$\mathrm{RBBC}$ is obtained. Such polytopic representation is used to demonstrate the closed-loop stability of the RBBC, despite parametric uncertainty.

In order to explain the functioning of the aforementioned RBBC consider the circuit shown in Figure 1. The proposed RBBC has a single power source $E$. By managing a switching strategy, the power flow from the source $E$ to the load $R$ is possible with some desired polarization. Three operation modes are allowed, and each one of them is selected by a proper switching activation and by a pulse width modulation (PWM) MOSFET activation:

(1) S1, S2 closed, S3, M2 open, and PWM switching on M1, Buck

(2) M1, S2 closed, S1, S3 open, and PWM switching on M2, Boost

(3) M2, S3 closed, S1, S2 open, and PWM switching on M1, Buck-Boost.

A nonpolarized capacitor $C$ is used and the load $R$ uses a wide voltage $v_{R}$ range with reversible flow current demand $i_{R}$.

Consider Mode 1; the equivalent circuit idealized as the well-known noninverting Buck converter is shown in Figure 2. S1 is PWM-switched, and an alternating voltage $E$ is supplied to the $R L C$ branch at high frequency when a voltage $0<v_{R} \leq E$ is needed.

The MOSFET M1 is modeled as a variable resistance $R_{1}(t)$ (Figure 3) with smooth transitions from very high to very low resistance and vice versa.

In such idealization, the voltage supplied to the $R L C$ branch can be taken as the average $V i(t)$ of a smooth time function (Figure 4):

$$
V i(t)=E \check{u}(t)
$$

where

$$
0 \leq \check{u}(t) \leq 1
$$




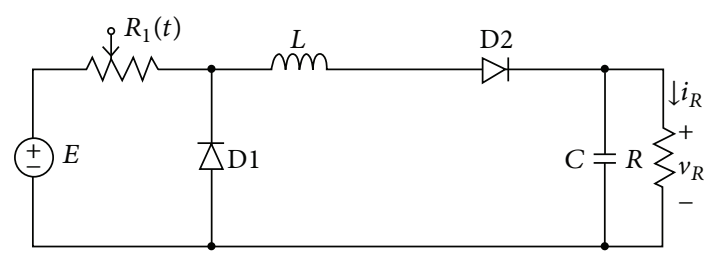

FIgURE 3: Idealized Mode 1 of the proposed RBBC.

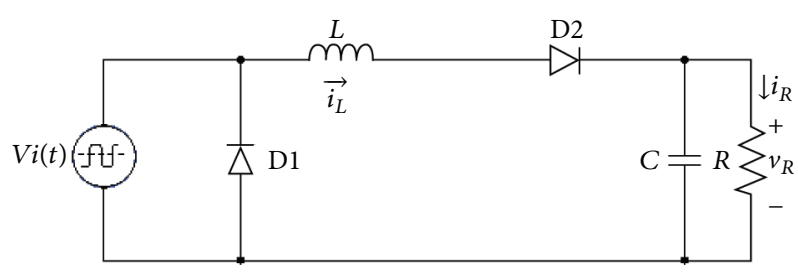

FIGURE 4: Idealized Mode I schematic.

is the PWM duty cycle. Equations that describe the dynamic behavior are

$$
\begin{gathered}
L \frac{d i_{L}}{d t}=\check{u} E-v_{R}, \\
C \frac{d v_{R}}{d t}=i_{L}-\frac{v_{R}}{R} .
\end{gathered}
$$

Note that system (3)-(4) coincides with the well-known averaged model of the Buck converter (see [41]). Substitution of (3) in (4) allows obtaining

$$
\ddot{v}_{R}=\frac{\check{u} E}{L C}-\frac{v_{R}}{L C}-\frac{\dot{v}_{R}}{R C}
$$

and the equivalent representation in state space with $x=$ $\left[v_{R}, \dot{v}_{R}\right]^{T}=\left[x_{1}, x_{2}\right]^{T}$ is

$$
\dot{x}=A x+B \check{u},
$$

where $[\cdot]^{T}$ denotes the transpose matrix operation, and

$$
\begin{aligned}
& A=\left[\begin{array}{cc}
0 & 1 \\
-\frac{1}{L C} & -\frac{1}{R C}
\end{array}\right], \\
& B=\left[\begin{array}{c}
0 \\
\frac{E}{L C}
\end{array}\right] .
\end{aligned}
$$

Consider Mode 2; the equivalent circuit can be idealized as the well-known noninverting Boost converter shown in Figure 5. M2 is PWM-switched and an alternating voltage $E$ is supplied to the $R L C$ branch at high frequency when a voltage $v_{R}>E$ is needed. Analogous modeling procedure allows obtaining the same state space representation (6) where $u(t)$ represents the one-minus-duty-cycle inverse of the PWM signal; this is,

$$
\frac{1}{1-\widehat{u}}=u(t)>1
$$

with $\widehat{u}$ as the duty-cycle percentage.

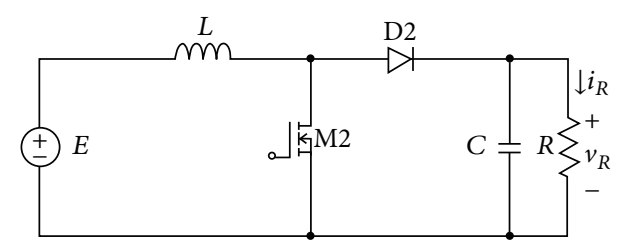

FIgure 5: Mode 2 of the proposed RBBC.

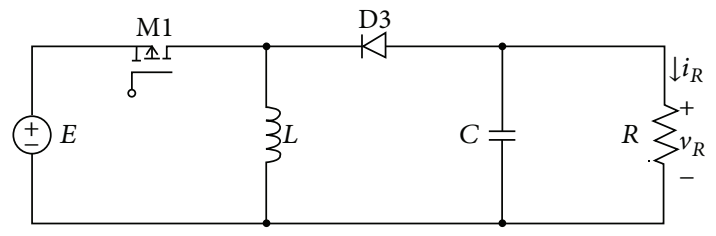

FIgURE 6: Mode 3 of the proposed RBBC.

In a similar way, Mode 3 shows the well-known inverting Buck-Boost converter shown in the Figure 6. M1 is PWMswitched and an alternating voltage $E$ is supplied to the $R L C$ branch at high frequency when a voltage $v_{R}<0$ is needed. Analogous modeling procedure allows obtaining the same state space representation (6) where $u(t)$ now represents

$$
\frac{\tilde{u}}{\tilde{u}-1}=u(t)<0
$$

with $\tilde{u}$ as the duty-cycle percentage.

By considering smooth transitions (allowing discharge of $L$ ) between modes, the resulting linear RBBC model is given by

$$
\dot{x}=A x+B u,
$$

where

$$
\begin{aligned}
& A=\left[\begin{array}{cc}
0 & 1 \\
-\frac{1}{L C} & -\frac{1}{R C}
\end{array}\right], \\
& B=\left[\begin{array}{c}
0 \\
\frac{E}{L C}
\end{array}\right],
\end{aligned}
$$

and the active mode depends on the value of $u$ :

(i) Mode 1: $0 \leq u \leq 1$.

(ii) Mode 2: $u>1$.

(iii) Mode 3: $u<0$.

Note that the theoretical output voltage $v_{R}$ in this configuration can reach any value from $-\infty$ to $\infty$; however, it is wellknown that in practice the voltage of Boost and Buck-Boost converters is limited due to nonideal components and also it is for the RBBC.

Consider the following voltage PD control law:

$$
u=k_{1} x_{1}+k_{2} x_{2}
$$


where $k_{1}$ and $k_{2}$ are the proportional and derivative gains, respectively. Note that a PI or PID controller can be used instead. The closed-loop system is represented then as

$$
\dot{x}=A_{R} x
$$

where

$$
A_{R}=\left[\begin{array}{cc}
0 & 1 \\
\frac{E k_{1}}{L C}-\frac{1}{L C} & \frac{E k_{2}}{L C}-\frac{1}{R C}
\end{array}\right] .
$$

In the following analysis, model (13) is addressed as nominal, because in this work the overall model's parameters are considered time-varying values. Using parametric ranges of uncertainty, a polytopic description is obtained as follows: consider that $L(t) \in[\underline{L}, \bar{L}], \forall t$; that is, the inductance $L(\cdot)$ varies in a known range from a maximum $\bar{L}$ to a minimum $\underline{L}$ which is inclusive. Similarly $R(t) \in[\underline{R}, \bar{R}]$ and $C(t) \in[\underline{C}, \overline{\bar{C}}]$. Then, a Linear Parameter Variant (LPV) system representation of (13) is

$$
\dot{x}=A_{R}(t) x=A_{R}(\theta(t)) x,
$$

where $\theta_{i} \leq \theta_{i}(t) \leq \overline{\theta_{i}} \forall i \in\{1,2,3,4\}$; that is, the matrix $A_{R}(t)$ is polytopic in the following sense:

$$
A_{R}(t)=\left\{A_{R}(\theta) \mid \sum_{i=1}^{4} A_{i} \theta_{i}(t)=A_{R}(t)\right\},
$$

where $\left(1 \geq \theta_{i}(t) \geq 0 \wedge \sum_{i=1}^{4} \theta_{i}(t)=1\right) \forall t$ and $\theta \in \mathbb{R}^{4}$ or equivalently

$$
\begin{aligned}
A_{R}(\theta)= & \theta_{1}\left[\begin{array}{cc}
0 & 1 \\
\underline{a_{21}} & \underline{a_{22}}
\end{array}\right]+\theta_{2}\left[\begin{array}{cc}
0 & 1 \\
\underline{a_{21}} & \overline{a_{22}}
\end{array}\right] \\
& +\theta_{3}\left[\begin{array}{cc}
0 & 1 \\
\overline{a_{21}} & \underline{a_{22}}
\end{array}\right]+\theta_{4}\left[\begin{array}{cc}
0 & 1 \\
\overline{a_{21}} & \overline{a_{22}}
\end{array}\right],
\end{aligned}
$$

where $a_{21}$ and $a_{22}$ represent the minimum values of the matrix entries for all $\bar{t}$; in a similar way, $\overline{a_{21}}$ and $\overline{a_{22}}$ represent the maximum possible values of the matrix entries for all $t$. That is,

$$
\begin{aligned}
& \underline{a_{21}}=\frac{E k_{1}-1}{\overline{L C}}, \\
& \overline{a_{21}}=\frac{\bar{E} k_{1}-1}{\underline{L C}}, \\
& \underline{a_{22}}=\frac{\underline{E} k_{2}}{\overline{L C}}-\frac{1}{R C}, \\
& \overline{a_{22}}=\frac{\bar{E} k_{2}}{\underline{L C}}-\frac{1}{\overline{R C}} .
\end{aligned}
$$

\section{Component Selection}

The converter components selection depends on application specifications as maximum voltage or current ripple, input voltage, and load current among others. In this work, an insight into their selection is presented and depends on the maximum inductor current ripple, switching frequency, source voltage, and output voltage [9]. Three inductor values are obtained, one for each mode, and the highest one is selected as the minimum inductance value required for a ripple specification; that is, the worst-case scenario is used to obtain a single inductor value:

$$
\underline{L}=\frac{1}{f_{\mathrm{sw}} \Delta_{I_{L}}} \max \left(v_{O, 1} \Lambda_{1}, E \Lambda_{2}, E \Lambda_{3}\right),
$$

where

$$
\begin{aligned}
& \Lambda_{1}=\left(1-\frac{v_{O, 1}}{E}\right) . \\
& \Lambda_{2}=\left(1-\frac{E}{v_{O, 2}}\right), \\
& \Lambda_{3}=\left(\frac{v_{O, 3}}{v_{O, 2}-E}\right)
\end{aligned}
$$

$f_{\text {sw }}$ is the switching frequency, $v_{\mathrm{O}, 1}$ is a nominal output voltage value in Mode $1, v_{\mathrm{O}, 2}$ is a nominal maximum output voltage value, $v_{\mathrm{O}, 3}<0$ is a nominal minimum output voltage value, and $\Delta_{I_{L}}$ is the maximum desired current ripple. Using the same method, saturation and maximum supported current of the inductor can be selected.

Semiconductor manufacturers recommend using low ESR capacitors to minimize the ripple on the output voltage, and the minimum value of $C$ is selected from the maximum of three values; that is, a worst-case $C$ capacitance value is selected:

$$
\underline{C}=\frac{i_{R, \max }}{f_{\mathrm{sw}} \Delta_{V_{R}}} \max \left(\Lambda_{1}, \Lambda_{2}, \Lambda_{3}\right),
$$

where $i_{R, \max }$ is the peak load current demand and $\Delta_{V_{R}}$ is the desired load voltage maximum ripple.

\section{Stability Analysis}

The control objective is to design a controller for the RBBC, such that stability of the trajectories of system (15) is ensured for parametric variation within specified design ranges.

Without loss of generality, the origin is considered the equilibrium point; note that a variable change calculated from an operating point can be performed in order to achieve it. Stability of a polytopic system can be ensured by the following result.

Proposition 1 (see [42]). Quadratic stability of system (15) is equivalent to the existence of $P \in \mathbb{R}^{4 \times 4}$ symmetric, positive definite matrix satisfying

$$
P A_{R, i}+A_{R, i}^{T} P \prec 0, \quad \forall i=1 \cdots 4,
$$

where $A_{R, i}$ denotes the ith vertex and $\prec 0$ denotes a negative definite matrix. 
In other words, it is enough to prove that all of the systems built with each vertex (in the following, vertex is used to identify the system built with the $i$ th vertex) are stable using a common Lyapunov function (CLF) to ensure that the polytopic system is quadratically stable even under arbitrarily fast parameter variation. Consider the CLF candidate:

$$
V=x^{T} P x=x^{T}\left[\begin{array}{ll}
\frac{c}{2} & 0 \\
0 & \frac{1}{2}
\end{array}\right] x=\frac{c}{2} x_{1}^{2}+\frac{1}{2} x_{2}^{2}
$$

with $c>0$. The time derivative along the trajectories of each vertex has the form

$$
\dot{V}=\left(c+\frac{E k_{1}}{L C}-\frac{1}{L C}\right) x_{1} x_{2}+\left(\frac{E k_{2}}{L C}-\frac{1}{R C}\right) x_{2}^{2},
$$

$\dot{V}<0$, if

$$
\begin{aligned}
c+\frac{E k_{1}}{L C}-\frac{1}{L C} & =0, \\
\frac{E k_{2}}{L C}-\frac{1}{R C} & <0
\end{aligned}
$$

and from the previous equality, with $k_{1}<0$,

$$
c=\frac{1}{L C}-\frac{E k_{1}}{L C}>0
$$

which reduces to

$$
k_{1}<\frac{1}{E} .
$$

From the inequality in (25) a second condition over $k_{2}$ is obtained:

$$
k_{2}<\frac{L}{E} .
$$

Since closed-loop involves a negative feedback for any vertex $\left(k_{1}<0, k_{2}<0\right)$, it is easy to determine that $A_{R, i}$ is Hurwitz for all $i$, and the stability under arbitrarily fast parameter variations (within bounded ranges) is ensured.

\section{Simulations}

In this section, representative simulations of the RBBC are presented. Simulations are performed in PSIM with a switching frequency of $10 \mathrm{kHz}$ and an integration time of $1 \mu \mathrm{s}$. Power source voltage of $10 \mathrm{~V}$ is used and the maximum duty cycle is established in $85 \%$ for M2 and M3; nominal values of components are $R=50 \Omega, L=10 \mu \mathrm{H}$, and $C=100 \mu \mathrm{F}$ with variation ranges for controller design of $\pm 20 \%$, inductor parasitic resistance of $0.01 \Omega$, MOSFET diode threshold voltage of $0.65 \mathrm{~V}$, MOSFET on resistance of $0.2 \Omega$, MOSFET diode resistance of $0.1 \Omega$, and SCR are used as switches with voltage drop, holding current and latching current of $0.1 \mathrm{~V}$ and $0.1 \mathrm{~A}$, respectively. In order to show robustness, changes of $R$ from $40 \Omega$ to $60 \Omega$ (squared function) are alternated at $20 \mathrm{~Hz}$. In Figure 7 a comparison of the output voltage $v_{R}$ versus a

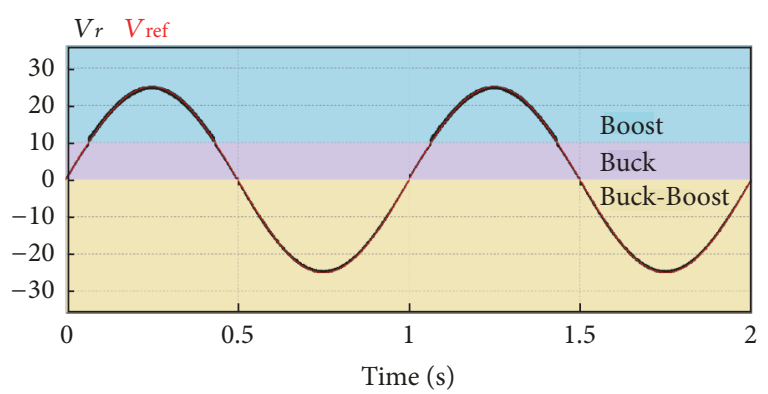

FIgURE 7: Sine reference response.

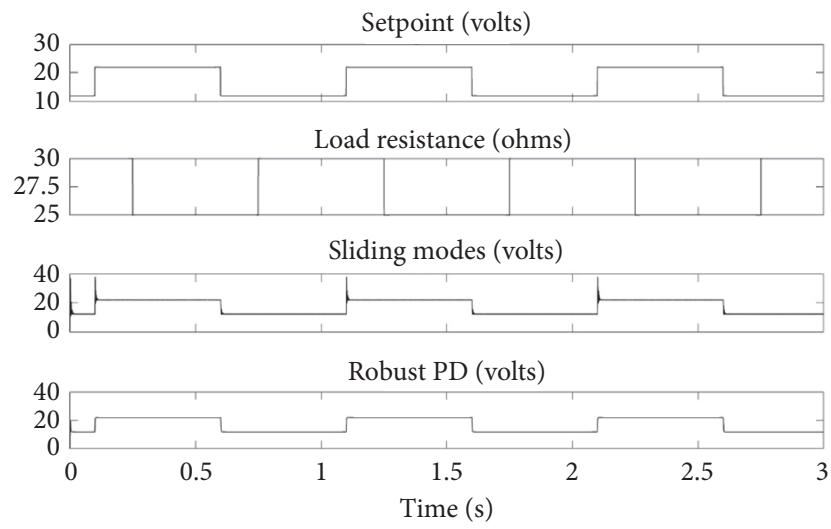

FIGURE 8: Sliding mode versus robust PD comparison for an abrupt load change.

sinusoidal reference is presented; note that the output voltage follows the reference with a fast response. The different colors represent the different operating modes: intersection of $\mathrm{Vr}$ with the blue color represents the Boost configuration (Mode 2), intersection of $V r$ with the purple color represents the Buck configuration (Mode 1), and intersection of $V r$ with the yellow color represents the Buck-Boost configuration (Mode 3). In this simulation hard switching between modes is used intentionally (without dead time or synchronization) in order to show the robustness of the controller. Note also that controller gains can be programmed differently for each mode in order to improve a particular desired response.

In order to show the benefits of the proposed control strategy, in Figure 8 a representative comparison of the dynamical behavior of the converter during parameter abrupt changes in the load resistance and in the setpoint is presented, between the proposed robust controller and a sliding mode controller. While in sliding mode a high overshoot is presented during setpoint changes; with the proposed controller this overshoot can be avoided by proper gain selection and even can be tuned intuitively; in sliding mode avoiding overshoots may imply the use of additional circuitry.

\section{Experimental Results}

In this section some of the relevant experimental results obtained by the implementation of the RBBC are presented. 


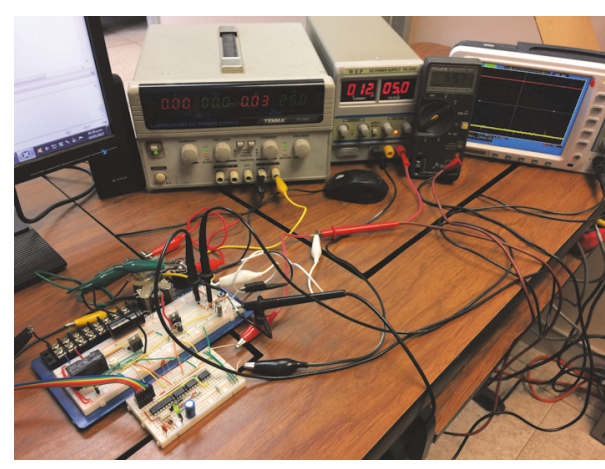

Figure 9: Experimental work bench.

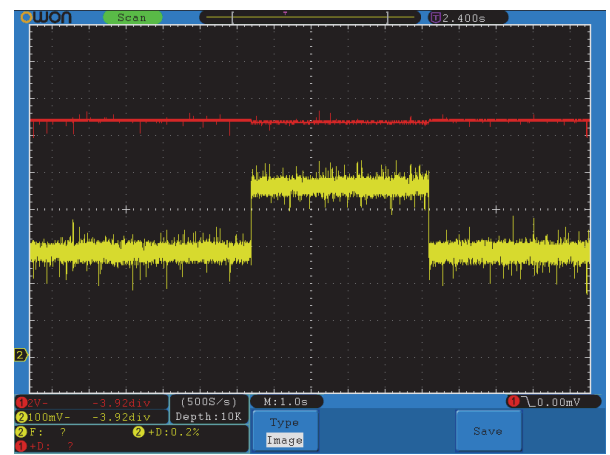

FIGURE 10: Buck mode parameter change response in closed-loop.

Figure 9 shows the implemented circuit. A simple double pole double throw is used for the switches. The robust control law and PWM generator are implemented in a cheap PIC16 with analog to digital converter and PWM generator. Trigger outputs are optically isolated from the converter and a voltage source $(E)$ of $25 \mathrm{~V}$ is used. Different load capacities are used and the controller gains fulfill the Section 4 conditions.

In Figure 10 the circuit output voltage is presented in red; load current is calculated by the voltage in $0.5 \Omega$ shown in yellow. For a regulated voltage (setpoint) of $12 \mathrm{~V}$, an abrupt change in load shows a higher current step calculated in $0.4 \mathrm{~A}$ and with a minimal voltage variation minor to $0.1 \mathrm{~V}$.

In Figure 11 the circuit output voltage is presented in red; due to high voltage, a load resistance of a higher value is used $(2 \mathrm{k} \Omega)$ for a regulated voltage (setpoint) of $70 \mathrm{~V}$; an abrupt change in load shows a higher current step calculated in $0.22 \mathrm{~A}$ and with a minimal voltage variation.

\section{Discussion}

The simulations and experimental data shown in the previous sections allow confirming that the proposed reconfigurable topology has benefit for a wide range of applications, such as vehicular one since the reversible power flow is possible with a simple reconfiguration. A new unified modeling technique is proposed and allows the use of a wide range of control techniques, even those that do not consider the switching reconfiguration characteristic of the $\mathrm{RBBC}$; that is, the unified model is valid for a Buck, Boost, and Buck-Boost

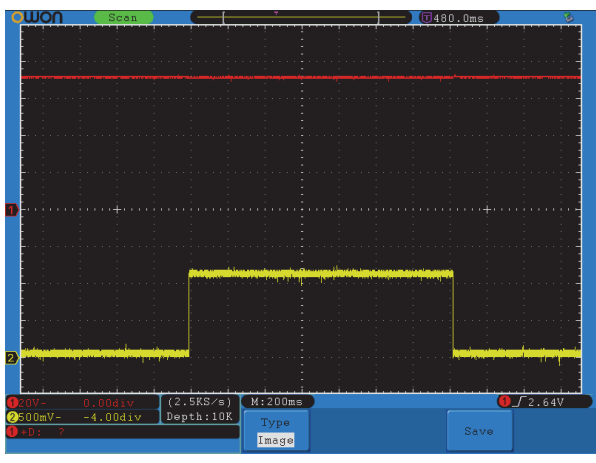

Figure 11: Boost mode parameter change response in closed-loop.

converter or a reconfigurable combination. The simulations and experimental data shown in the previous sections allow validating the analytic results for modeling, controller design, and stability.

While other control techniques, as sliding mode, are beneficial for implementations, where the high overshoot, no-adjustment, and settling time are not a critic issue, the proposed control strategy allows performing a fine tuning, even for the nonexpert. That is, sliding mode and other control techniques have large benefits; however, they are very sensitive to large changes in the parameters. In contrast, the presented control strategy stabilizes the voltage output even when abrupt changes on the parameters occur, as long as they vary within the design bounds. Even more, since voltage feedback is used the implementation cost is very low.

\section{Conclusions}

In this work, a new reconfigurable converter (RBBC) is presented. The reconfigurable converter has three operating modes/configurations, Buck, Boost, and Buck-Boost that are possible with only two MOSFETs which implies that the implementation cost is very low. In this reconfigurable converter, the output voltage can vary within a wide range from negative to high positive values (Boost) and the reconfiguration can be done on the fly. In view of the above, the presented reconfigurable converter can be used in a wide range of applications, for example, in electric propulsion/traction applications where forward and reverse direction are required.

A dynamical model for the reconfigurable converter is obtained in a unified sense for the Buck, Boost, and BuckBoost configurations. That is, the dynamical model structure is the same and the control input $u$ defines the smooth reconfiguration and the output level. Thus, the reconfigurable converter and the dynamical model can be used with a wide range of different control techniques. Even more, the model can be used for single configurations or a combination of them, for example, a reconfigurable Buck and Boost converter (without the Buck-Boost).

Moreover, in this work the methodology for the design of a robust controller for the reconfigurable converter is presented. The closed-loop stability is demonstrated by using a polytopic model and a common Lyapunov function and 
provides several advantages as simplicity, low implementation cost by voltage feedback, and adjustable gains. Comparative results are provided in order to illustrate the dynamical behavior against changes in parameters as capacitance, inductance, load resistance, and input voltage, with respect to a sliding mode controller.

\section{Nomenclature}

$\begin{array}{ll}C, \underline{C}, \bar{C}: & \begin{array}{l}\text { Output capacitor values, nominal, } \\ \text { minimum, and maximum }\end{array} \\ \Delta_{I_{L}}, \Delta_{V_{R}}: & \begin{array}{l}\text { Maximum (design) current and voltage } \\ \text { ripple }\end{array} \\ E, \underline{E}, \bar{E}: & \begin{array}{l}\text { Power source voltage values, nominal, } \\ \text { minimum, and maximum }\end{array} \\ f_{\text {sw }}: & \text { PWM switching frequency } \\ i_{L}: & \text { Inductance current value } \\ i_{R, \text { max }}: & \text { Peak (design) load current demand } \\ k_{1}, k_{2}: & \text { Controller gains } \\ L, \underline{L}, \bar{L}: & \text { Inductance values, nominal, minimum, } \\ R, \underline{R}, \bar{R}: & \text { and maximum } \\ & \text { Output resistor values, nominal, } \\ R_{1}, R_{2}: & \text { minimum, and maximum } \\ \check{u}: & \text { Idealized resistance values of the MOSFET } \\ \widehat{u}: & \text { Duty cycle in Mode 1 (Buck) } \\ \tilde{u}: & \text { Duty cycle in Mode 2 (Boost) } \\ u: & \text { Duty cycle in Mode 3 (Buck-Boost) } \\ V i: & \text { Control input of the RBBC } \\ V_{O, 1}, V_{O, 2}, V_{O, 3}: & \text { Idealized averaged supply voltage } \\ & \text { Nominal (design) output voltage in Mode } \\ v_{R}: & \text { Output resistor voltage. }\end{array}$

\section{Conflicts of Interest}

The authors declare no conflicts of interest for this paper.

\section{References}

[1] R. W. Erickson and D. Maksimovic, Fundamentals of Power Electronics, Springer Science and Business Media, 2007.

[2] D. G. Holmes and T. A. Lipo, Pulse Width Modulation for Power Converters: Principles and Practice, vol. 18, John Wiley and Sons, 2003.

[3] A. Emadi, A. Khaligh, Z. Nie, and Y. J. Lee, Integrated Power Electronic Converters and Digital Control, CRC Press, 2009.

[4] S. Bacha, I. Munteanu, and A. I. Bratcu, "Power electronic converters modeling and control," Advanced Textbooks in Control and Signal Processing, vol. 454, p. 454, 2014.

[5] S. Kaboli, "Reliability in power electronics and electrical machines: industrial applications and performance models: industrial applications and performance models," IGI Global, 2016.

[6] C. Harskind and M. Morack, A History of Mercury-Arc Rectifiers in North America, IEEE IA Society, IEEE Service Center, Piscataway, NJ, USA, 1987.

[7] M. Poshtan, S. Kaboli, and J. Mahdavi, "On the suitability of modeling approaches for power electronic converters," in Proceedings of the International Symposium on Industrial Electronics 2006 (ISIE '06), pp. 1486-1491, Canada, July 2006.
[8] F. Vasca and L. Iannelli, Dynamics and Control of Switched Electronic Systems: Advanced Perspectives for Modeling, Simulation and Control of Power Converters, Springer, 2012.

[9] L. Corradini, D. Maksimovic', P. Mattavelli, and R. Zane, Digital Control of High-Frequency Switched-Mode Power Converters, vol. 48, John Wiley and Sons, 2015.

[10] J. W. Kolar, J. Biela, S. Waffler, T. Friedli, and U. Badstuebner, "Performance trends and limitations of power electronic systems," in Proceedings of the 6th International Conference on Integrated Power Electronics Systems (CIPS '10), 2010.

[11] M. Mansouri, S. H. Aghay Kaboli, J. Selvaraj, and N. A. Rahim, "A review of single phase power factor correction AC-DC converters," in Proceedings of the IEEE Conference on Clean Energy and Technology (CEAT '13), pp. 389-394, Malaysia, 2013.

[12] M. Mansouria, S. H. A. Kaboli, J. Selvaraj, and N. A. Rahim, "Online adaptive Power Factor Correction controller for DCDC converters," in Proceedings of the 3rd IET International Conference on Clean Energy and Technology (CEAT '14), Malaysia, November 2014

[13] S. S. Sebtahmadi, H. Pirasteh, S. H. Aghay Kaboli, A. Radan, and S. Mekhilef, "A 12-sector space vector switching scheme for performance improvement of matrix-converter-based DTC of im drive," IEEE Transactions on Power Electronics, vol. 30, no. 7, pp. 3804-3817, 2015.

[14] S. Kaboli, J. Selvaraj, and N. Rahim, "Performance evaluation of multi-carrier PWM methods for solar cells powered multilevel inverters," in Proceedings of the 4th IET Clean Energy and Technology Conference (CEAT '16), pp. 6-56, Kuala Lumpur, Malaysia, 2016.

[15] S.-W. Lee and H.-L. Do, "Boost-integrated two-switch forward AC-DC LED driver with high power factor and ripple-free output inductor current," IEEE Transactions on Industrial Electronics, vol. 64, no. 7, pp. 5789-5796, 2017.

[16] M. A. Dalla Costa, T. B. Marchesan, J. S. Da Silveira, Á. R. Seidel, R. N. Do Prado, and J. M. A. Lvarez, "Integrated power topologies to supply HPS lamps: A comparative study," IEEE Transactions on Power Electronics, vol. 25, no. 8, pp. 2124-2132, 2010.

[17] S. Saponara, P. Tisserand, P. Chassard, and D.-M. Ton, "Design and measurement of integrated converters for belt-driven starter-generator in $48 \mathrm{v}$ micro/mild hybrid vehicles," IEEE Transactions on Industry Applications, vol. 53, no. 4, pp. 39363949, 2017.

[18] O. Hegazy, R. Barrero, J. Van Mierlo, P. Lataire, N. Omar, and T. Coosemans, "An advanced power electronics interface for electric vehicles applications," IEEE Transactions on Power Electronics, vol. 28, no. 12, pp. 5508-5521, 2013.

[19] S.-Y. Kim, S. Choe, S. Ko, and S.-K. Sul, "A Naval Integrated Power System with a Battery Energy Storage System: Fuel efficiency, reliability, and quality of power," IEEE Electrification Magazine, vol. 3, no. 2, pp. 22-33, 2015.

[20] C.-Y. Hsieh, M. Moallem, and F. Golnaraghi, "A bidirectional boost converter with application to a regenerative suspension system," IEEE Transactions on Vehicular Technology, vol. 65, no. 6, pp. 4301-4311, 2016.

[21] A. Emadi, S. S. Williamson, and A. Khaligh, "Power electronics intensive solutions for advanced electric, hybrid electric, and fuel cell vehicular power systems," IEEE Transactions on Power Electronics, vol. 21, no. 3, pp. 567-577, 2006.

[22] Y. R. Li and W. G. Hurley, "Editorial Special Issue on Sustainable Energy Systems Integration," IEEE Journal of Emerging and 
Selected Topics in Power Electronics, vol. 3, no. 4, pp. 854-857, 2015.

[23] B. Novakovic and A. Nasiri, "Modular multilevel converter for wind energy storage applications," IEEE Transactions on Industrial Electronics, vol. 64, no. 11, pp. 8867-8876, 2017.

[24] S. Dusmez, X. Li, and B. Akin, "A new multiinput three-level DC/DC converter," IEEE Transactions on Power Electronics, vol. 31, no. 2, pp. 1230-1240, 2016.

[25] C. Aguilar, A. Vazquez, F. Canales, and J. Gordillo, "Integrated DC AC converter as power conditioner for fuel cell based system," IEEE Latin America Transactions, vol. 14, no. 5, pp. 2107-2113, 2016.

[26] C. Cecati, H. A. Khalid, M. Tinari, G. Adinolfi, and G. Graditi, "DC nanogrid for renewable sources with modular DC/DC LLC converter building block," IET Power Electronics, vol. 10, no. 5, pp. 536-544, 2017.

[27] K. Strunz, E. Abbasi, and D. N. Huu, "DC microgrid for wind and solar power integration," IEEE Journal of Emerging and Selected Topics in Power Electronics, vol. 2, no. 1, pp. 115-126, 2014.

[28] D. Ronanki and S. S. Williamson, "Modular multilevel converters for transportation electrification: challenges and opportunities," IEEE Transactions on Transportation Electrification, vol. PP, no. 99, p. 1, 2018.

[29] T. Orlowska-Kowalska, F. Blaabjerg, J. Rodrguez, and T. Orłowska-Kowalska, Advanced and Intelligent Control in Power Electronics and Drives, vol. 531, Springer, 2014.

[30] H. Asadi, S. H. Aghay Kaboli, A. Mohammadi, M. Oladazimi, Z. Zeng, and Y. Li, "Fuzzy-control-based five-step Li-ion battery charger by using AC impedance technique," in Proceedings of the Fourth International Conference on Machine Vision (ICMV '11), vol. 8349, Singapore.

[31] H. Asadi, S. H. A. Kaboli, A. Mohammadi, and M. Oladazimi, "Fuzzy-control-based five-step Li-Ion battery charger by using AC impedance technique," in Proceedings of the Fourth International Conference on Machine Vision (ICMV '12): Machine Vision, Image Processing, and Pattern Analysis, vol. 8349, 2012.

[32] S. H. A. Kabolia, M. Mansouri, J. Selvaraj, and N. A. Rahim, "Controlling methods for Power Factor Correction of storage devices connected into smart grid," in Proceedings of the 3rd IET International Conference on Clean Energy and Technology (CEAT '14), pp. 1-6, Malaysia, November 2014.

[33] S. H. A. Kaboli, Fuzzy logic control for permanent magnet motor [Ph.D. thesis], Jabatan Kejuruteraan Elektrik, Fakulti Kejuruteraan, Universiti Malaya, 2012, Ph.D. dissertation.

[34] M. Mansouri, S. H. A. Kaboli, J. Ahmadian, and J. Selvaraj, "A hybrid Neuro-Fuzzy - P.I. speed controller for B.L.D.C. enriched with an integral steady state error eliminator," in Proceedings of the 2012 IEEE International Conference on Control System, Computing and Engineering, ICCSCE 2012, pp. 234-237, Malaysia, November 2012.

[35] S. H. A. Kaboli, M. Mansouri, J. Selvaraj, and N. B. A. Rahim, "A hybrid adaptive neural-fuzzy tuned P.I. controller based unidirectional boost P.F.C. converter feeds B.L.D.C. drive," in Proceedings of the 4th Annual International Power Electronics, Drive Systems and Technologies Conference, PEDSTC 2013, pp. 176-181, Iran, February 2013.

[36] S. Hr. Aghay Kaboli, A. Mohammadi, A. Fallahpour, J. Selvaraj, and N. Abd Rahim, Fuzzy logic based encoder-less speed control of PMSM for hub motor drive, in Fuzzy Control Systems: Design, Analysis and Performance Evaluation, Nova Science, Analysis and Performance Evaluation, 2016.
[37] S. S. Sebtahmadi, H. B. Azad, S. H. Kaboli, M. D. Islam, and S. Mekhilef, "A PSO-DQ Current Control Scheme for Performance Enhancement of Z-Source Matrix Converter to Drive IM Fed by Abnormal Voltage," IEEE Transactions on Power Electronics, vol. 33, no. 2, pp. 1666-1681, 2018.

[38] A. Khaligh, A. M. Rahimi, and A. Emadi, "Modified pulseadjustment technique to control DC/DC converters driving variable constant-power loads," IEEE Transactions on Industrial Electronics, vol. 55, no. 3, pp. 1133-1146, 2008.

[39] T. J, Journal of Renewable Energy, InTech, 2009.

[40] V. Vesely and D. Rosinova, "Robust MPC controller design for switched systems using multi-parameter dependent Lyapunov function , International Journal of Innovative Computing," vol. 10, pp. 269-280, 2014.

[41] H. Sira-Ramrez and R. Silva-Ortigoza, Control Design Techniques in Power Electronics Devices, Springer Science Business Media, 2006.

[42] S. Boyd, L. El Ghaoui, E . Feron, and V. Balakrishnan, Linear Matrix Inequalities in System and Control Theory, SIAM, Philadelphia, Pa, USA, 1994. 


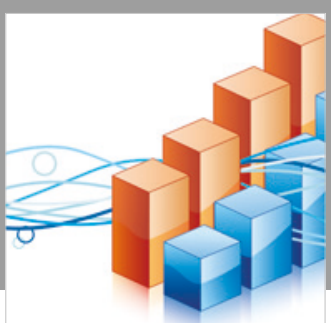

Advances in

Operations Research

\section{-n-m}
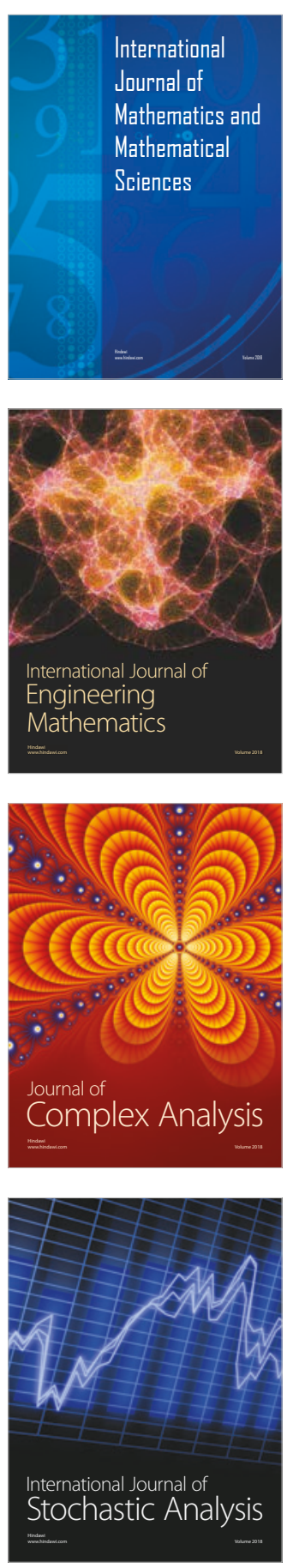
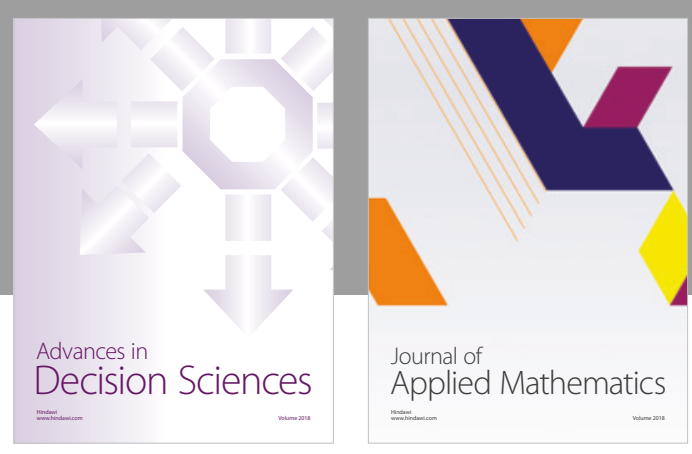

Journal of

Applied Mathematics
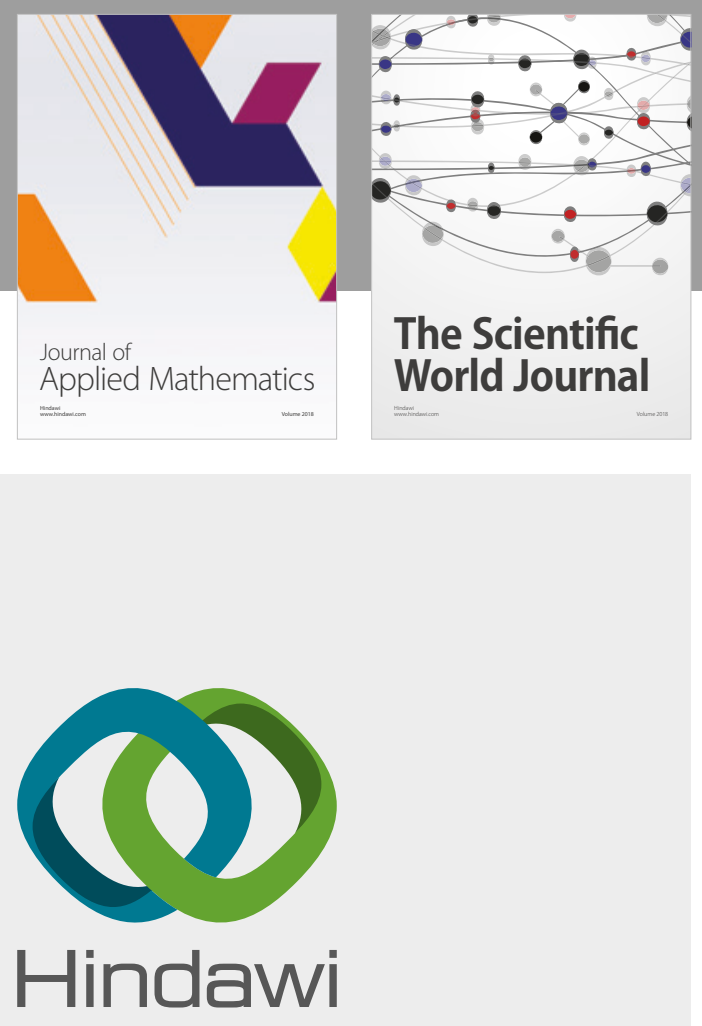

Submit your manuscripts at

www.hindawi.com

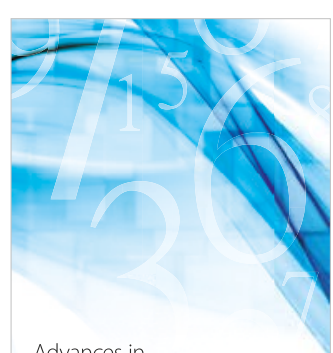

Advances in
Numerical Analysis
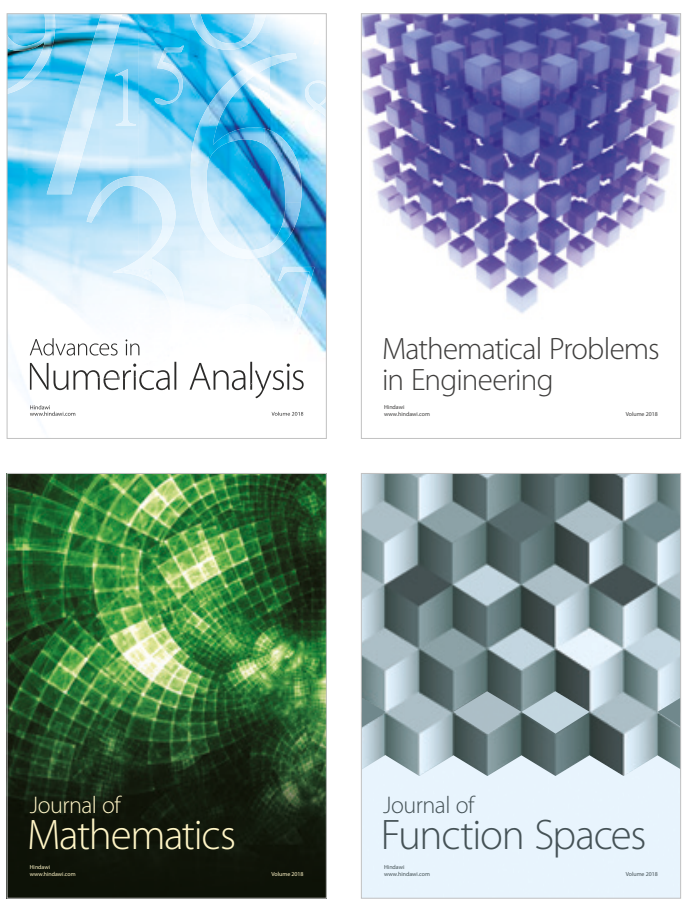

Mathematical Problems in Engineering

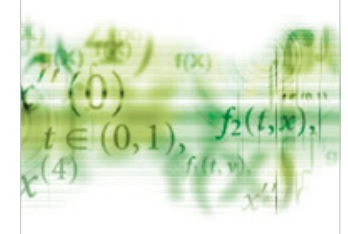

International Journal of

Differential Equations

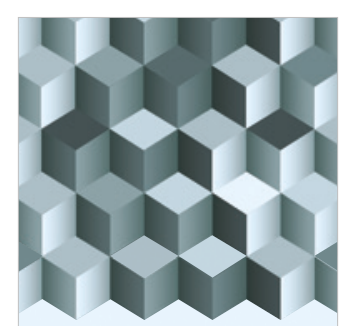

Journal of

Function Spaces

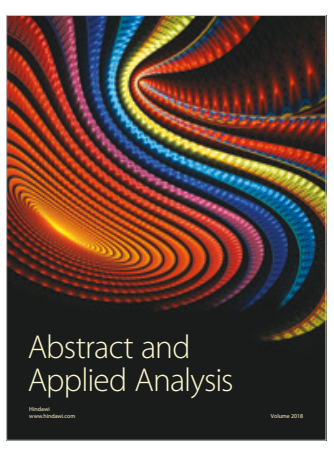

The Scientific

World Journal

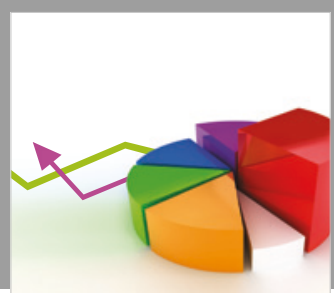

Journal of

Probability and Statistics
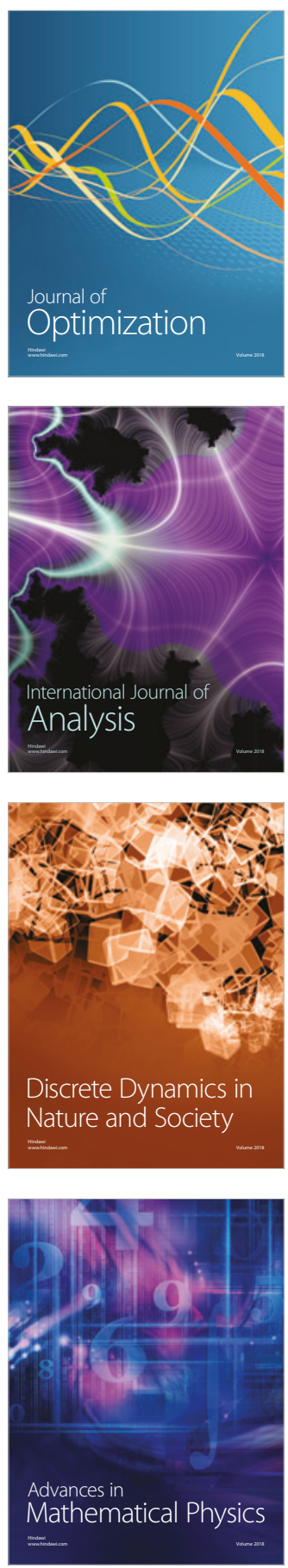